\title{
ARCHITECTURAL HERITAGE VISUALIZATION USING INTERACTIVE TECHNOLOGIES
}

\author{
A. T. Albourae ${ }^{\mathrm{a}}$, C. Armenakis ${ }^{\mathrm{a}}$, M. Kyan ${ }^{\mathrm{b}}$ \\ ${ }^{a}$ Geomatics Engineering, Dept. of Earth \& Space Science \& Engineering, \{aalbourae@kau.edu.sa\} \{armenc@yorku.ca\} \\ ${ }^{\mathrm{b}}$ Dept. of Electrical Engineering \& Computer Science, \{mkyan@cse.york.ca\} \\ ${ }^{\mathrm{a}, \mathrm{b}}$ Lassonde School of Engineering, York University, Toronto, Ontario, Canada
}

\section{Commission II}

KEY WORDS: Heritage, Visualization, 3D Modelling, Augmented Reality, HBIM

\begin{abstract}
:
With the increased exposure to tourists, historical monuments are at an ever-growing risk of disappearing. Building Information Modelling (BIM) offers a process of digitally documenting of all the features that are made or incorporated into the building over its life-span, thus affords unique opportunities for information preservation. BIM of historical buildings are called Historical Building Information Models (HBIM). This involves documenting a building in detail throughout its history. Geomatics professionals have the potential to play a major role in this area as they are often the first professionals involved on construction development sites for many Architectural, Engineering, and Construction (AEC) projects. In this work, we discuss how to establish an architectural database of a heritage site, digitally reconstruct, preserve and then interact with it through an immersive environment that leverages BIM for exploring historic buildings. The reconstructed heritage site under investigation was constructed in the early $15^{\text {th }}$ century. In our proposed approach, the site selection was based on many factors such as architectural value, size, and accessibility. The 3D model is extracted from the original collected and integrated data (Image-based, range-based, CAD modelling, and land survey methods), after which the elements of the 3D objects are identified by creating a database using the BIM software platform (Autodesk Revit). The use of modern and widely accessible game engine technology (Unity3D) is explored, allowing the user to fully embed and interact with the scene using handheld devices. The details of implementing an integrated pipeline between HBIM, GIS and augmented and virtual reality (AVR) tools and the findings of the work are presented.
\end{abstract}

\section{INTRODUCTION}

Cultural and historical heritages form an integral part of the national identity. Heritage sites, structures and monuments play a major role in the collective memory of a society. Such sites act as a bridge between the present and the past, and offer attractive landmarks to the city, while attracting foreign tourists, which, in turn, can help boost local economies. Therefore, there is an increasing need for proper documentation and preservation of heritage sites and monuments using modern technologies. Sufficient documentation helps to monitor the unavoidable degradation of sites due to natural disasters, negligence or traumatic events, such as war. Together, this helps build better maintenance and more effective management systems and tools for heritage sites.

Electronic documentation (e-documentation) is the documentation of targets in digital formats with the help of audio-visual tools. This technology will not only help to capture the most intricate details of sites, but also helps to reach a much larger audience. The information gathered through this technology can be utilised in a plethora of interesting applications in the classroom, coaching, or even gaming.

In the past, heritage documentation mainly relied on human interpretation such as hand drawings, on-site measurement, sculptures, and pictures, which was time consuming and less precise. The power of technology has been increasingly utilized in recent years due to the evolution of architectural visualization from paper drawing to screen displaying to virtual 3D, which provided for better understanding, visual communication and interaction within a scene; it also provided additional ways to capture and display the materials, colors, decorative information, and so forth, in order to obtain more accurate results (Fig. 1).

Virtual Reality (VR) is defined by Steuer (1992) as "a real or simulated environment in which a perceiver experiences telepresence". The use of e-documentation has the potential to integrate with an enhanced virtual environment where the user can experience a virtual walk through the heritage site without having to visit it physically. It also can help tourists in choosing potential sites to visit before planning their travel. In a similar way, an augmented reality (AR) system is a combination between real and computer-created information interactively in a real environment, and in real time which aligns virtual objects with real world/physical ones (Höllerer \& Feiner, 2004). Thus, it can also be used to project computer-generated objects onto the heritage site to digitally re-construct a particular time in history, giving the user a more fulfilling experience.

Buckland \& Wilcock (1973) predicted that computers would be used to reconstruct archaeological sites. Indeed, the first step towards 3D e-documentation of archaeological objects was published little more than 10 years later, in 1985, by Leo Biek. Later, extensive research was conducted on electronic and digital documentation of sites and artefacts, such as: The Roman Bath and the Roman military bathhouse at Caerleon, South Wales (Arnold et al., 1989); Michelangelo's sculptures (ten statues, including the David) in Florence, Italy (Levoy et

\footnotetext{
* Corresponding author
} 
al., 2000); and, An ancient marble map of Rome, the Forma Urbis Romae, approximated $18 \mathrm{~m}$ in width by $13 \mathrm{~m}$ in height which constructed in the early 3rd century (Koller \& Levoy, 2006).

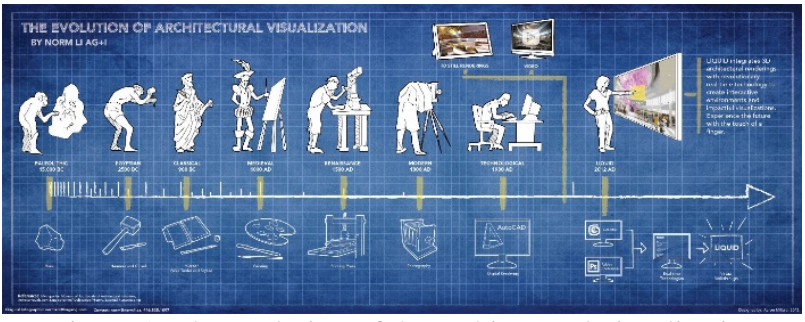

Figure 1. The evolution of the architectural visualization (Metropolitan Museum of Art. Millard, A., 2012)

\section{BACKGROUND}

Al-Balad, the historical area of Jeddah, is situated on the eastern shore of the Red Sea (Fig. 2); and has recently been recognised as a United Nations Organization of Education, Science and Culture (UNESCO) World Heritage Centre, in 2014. Jeddah had acted as a major port for Indian Ocean trade routes, channelling pilgrims and goods to Makkah, since the $14^{\text {th }}$ century. The distinctive architectural tradition that developed in this area was the result of a fusion of local coastal coral building traditions with crafts and ideas arriving with the traders and pilgrims. Unfortunately, rapid urbanization of the area and poor maintenance of the structures resulted in irreversible loss to this heritage (Al-Gabban, A., 2013). Thus, urgent documentation and preservation are needed. Moreover, with the influx of tourists, it is necessary to provide proper guidance information and increased context awareness.

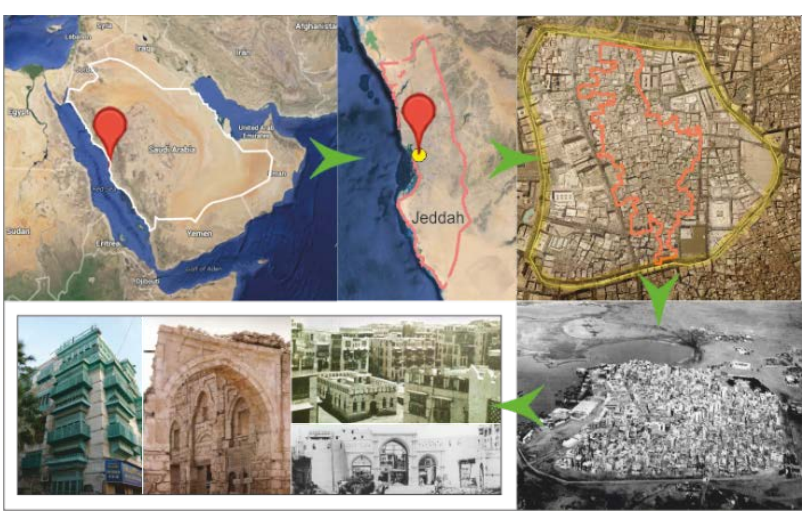

Figure 2. The geographic location of the study area

One of the factors that make the Jeddah Historical City a very suitable case for application of the mentioned documentation and modelling techniques is that such application will both digitally preserve the heritage elements and provide the global audience with a more engaging historical experience.

Although the heritage of the Jeddah Historical City is well documented, not many papers have discussed the importance of preserving it electronically. Apart from the thorough documentation of the Roshans in the Jeddah Historical City, carried out by Alitany (2014) using a method integrating imagebased modelling and CAD modelling technologies, only a few studies are available where particular buildings of the city have been documented and modelled. To facilitate a detailed study of the architectural elements of historical monuments, Baik et al (Baik 2015) have presented a method which integrates Jeddah
Historic Building Information Modelling (JHBIM) and 3D Geographic Information System (3D GIS). Using this integrated approach, they have developed a model of Nasif Historical House. This model is semantically enriched with nonarchitectural aspects, including: the material used in the composition of the building's parts, the historical context of building, the history of reparations that took place on the building, and so forth. Such information is of interest to tourists. However, augmented and virtual reality (AVR) tools will assist significantly to present the historical data to tourists. Our proposed approach will bring these methods together to cater to the needs of both tourists and researchers, and will generate an exhaustive reference database for future heritage preservation and restoration projects.

The present status of documentation of Jeddah Historical City does not yet meet these needs. Moreover, there is a lack of applications that can take care of the extensive requirements for documentation, preservation and tourism. Therefore, the proposed study aims to create a holistic application for the heritage preservation of Jeddah Historical City, with the following goals: to digitally preserve and reconstruct the site, interact with it, increase contextual awareness and attract global tourists.

\section{RELATED WORKS}

For 3D-model generation of heritage sites, a number of techniques for model generation are available that can be used individually or collaboratively. According to many researchers (Boehler \& Marbs, 2004; Kadobayashi et al., 2004; Grussenmeyer et al., 2008; Remondino, F., 2014), these techniques are actually complementary, and no one strategy can fulfill all the requirements. Rather, an integrated/hybrid approach should be utilized to overcome the limitations of the individual methods. The major techniques and their applicability are summarised in Figure 3.

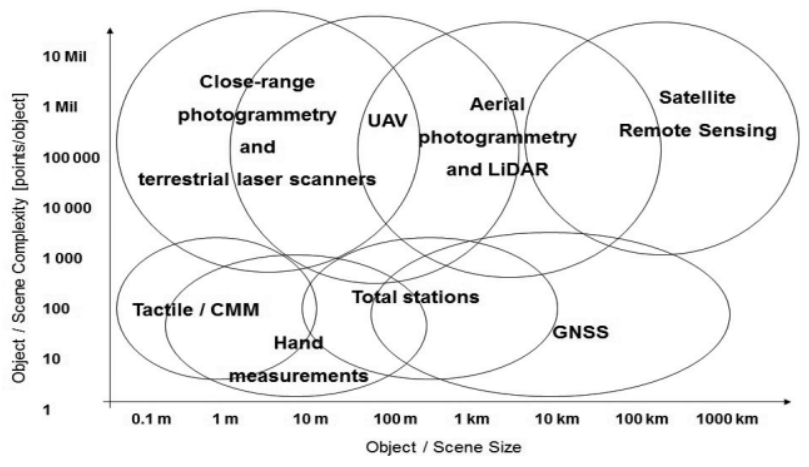

Figure 3. Model reconstruction methods (Remondino, 2014)

Electronic documentation of the site of interest, Jeddah Historical City, poses some unique challenges because of its construction and the amount of details that need to be extracted to create a truly descriptive model. Due to the vast size of the site, modelling using aerial photogrammetry seems to be the natural choice for documentation. However, because of the alleys and overhung Roshans present in the site, much of the building facades are inaccessible by aerial photogrammetry. The same reasons also create barriers for data acquisition from the ground. In addition, the roofs and building interior need to be considered. Therefore, a novel approach needs to be devised that integrates both aerial and ground-based data acquisition.

In addition, the lighting conditions in the alleys and zones beneath the Roshans may not always be suitable for image- 
based methods, and also laser-based technologies alone may not be suitable to extract the level of detail required for the project Alitany (2014). As such, it is absolutely necessary to integrate the two methods in some cases for ground-based data acquisition as needed. In this proposed work, a novel workflow is created that encompasses all three methods: Close Range Photogrammetry (CRP), Terrestrial Laser Scanning (TLS) and Structure from Motion - Multi View Stereo (SfM-MVS). Moreover, to enhance geometric accuracy, CAD modelling will also be incorporated.

Historic Building Information Modelling (HBIM) enables the parametric and procedural modelling of historical objects and buildings from laser scan or photogrammetric survey data (Dore \& Murphy, 2012). HBIM includes a plug-in library of architectural objects for BIM software platforms and a semiautomatic system for plotting these objects to photogrammetric survey and/or laser scan data. After that, the next stage will involve the integration of the 3D model into a 3D GIS for further management and analysis in order to semantically enrich the non-architectural information such as vector datasets, raster datasets, and attribute data.

\section{METHODOLOGY}

As the target of the proposed work is to create a holistic application for immersive environment applications, the final output will have multiple facets, and depending on the requirement, 3D models with different levels of details and links to contextual information. To use the created model for the proposed holistic application, it will be required to feed the models to AVR platforms and to collate the necessary historical and architectural information that will be useful for documentation, preservation, and tourism purposes. The capabilities of the currently available VR and AR tools will be blended and used in an integrated way, enabling the users to virtually experience and interact with the site from remote locations. The work is based on a digital library of the heritage architectural elements of the selected site in order to study and understand the evolution of the architectural heritage of the city. This library will also be helpful for possible future applications, such as physical reconstruction of degraded monuments, gaming designs and educational purposes. Therefore, the work has the following components:

- A workflow developed to integrate LiDAR-Based, ImageBased and CAD Modelling Technologies and utilize it to generate a 3D model of the target site.

- Creation of a 3D models library of heritage architectural elements with high levels of detail and geometrical accuracy.

- A thorough study of the heritage architectural elements to provide the future users with relevant data to understand the heritage and its evolution.

- 3D models implemented using BIM tools integrated into a Geospatial information system to provide semantically rich information models and seamless interaction with a virtual and augmented reality system.

- Use and management of the output of 3D models for the development of a holistic AVR application, which will provide the users with an immersive experience complemented with interactive contextual information.

In our proposed approach, the site selection was based on many factors such as architectural value, size, and accessibility. The 3D model is extracted from the original collected and integrated data (Image-based, range-based, CAD modelling, and traditional survey method), after which the elements of the 3D object will be identified by creating a database using the BIM software platform. Revit software, for instance, is a BIM modelling platform (Autodesk, 2011), which can be used to create a BIM type analyses on the 3D object.

In addition, an integration of the 3D BIM model into a 3D GIS will be implemented for further management and analysis. Texture details are then reapplied to generate a highly detailed rendition of the object from all angles that can be visualized in a specifically tailored web application or tested in real-time, with full fidelity, using a game engine like Unity3D (Unity, 2017). Then, the virtual and augmented handheld devices can be used to present the information to the user (Fig. 4).

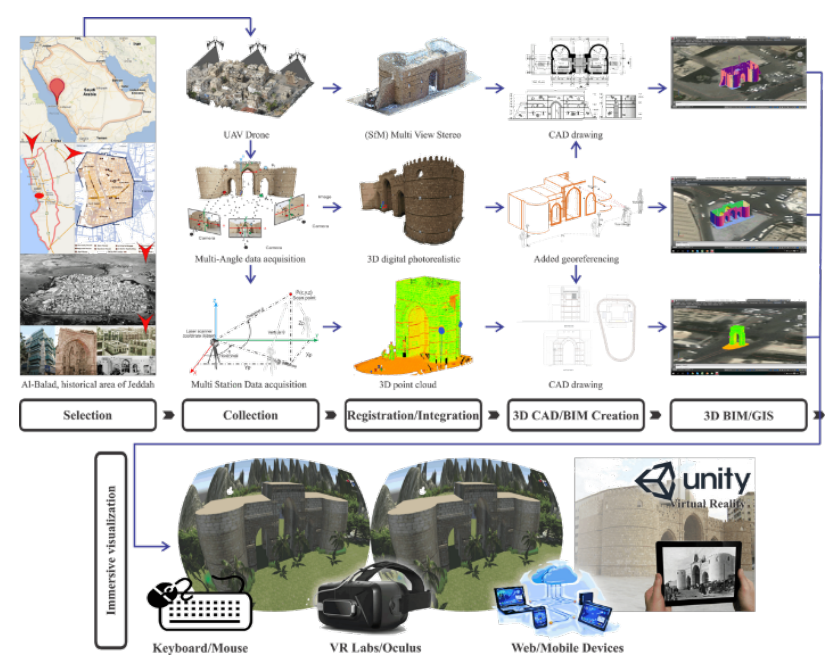

Figure 4. Methodology workflow

\subsection{Integration of Data Acquisition Methods and Generation of 3D Models}

In the first part of this proposed work, four types of methods are used and integrated as needed; namely, Close Range Photogrammetry (CRP), Terrestrial Laser Scanning (TLS), Structure from Motion-Multi View Stereo (SfM-MVS) and CAD modelling in order to have complete 3D model details. The appropriate integration of the point-clouds to generate the most accurate 3D model requires careful inspection of the acquired data and creation of a suitable workflow. Thus, the 3D models generated are used in the following stages of work. A schematic of the proposed integration method is presented in Figure 5.

\subsection{Generation of an Architectural Element Library and Study of the Heritage and Its Evolution}

To generate a library of the architectural elements of the created 3D model, it is required to identify and categorize the different architectural elements of the site. For example, the typical historical buildings of the area have distinguishable features such as:

i. Typical wooden windows, 'Roshans' (large projecting three-sided wooden structure on building facades)

ii. Carved and ornamental doors (mostly used for main entrances)

iii. Creative forms of lattice work and fretted decorations such as Shish or Mashrabiya, which are mostly integrated into Roshans

iv. Sgraffito (decorative plasterwork) (Alitany, 2014). 
This proposed library consists of models of such features, properly categorized and structured. A thorough study of the elements and their histories will be carried out to provide information about the elements in order to facilitate future research and studies on the evolution of heritage. In addition, it will act as a reference point for required reconstruction and model refinement work. Moreover, it will also help the designers to work with period movies, games and educational applications.

\subsection{HBIM integrated with Geospatial Information System.}

Building Information Modelling (BIM) is a new standard for CAD drafting in the Architecture, Engineering, Construction, and Owner/Operator (AECO) industries. This technology will play an important role in the design, reconstruction, maintenance of buildings, and for managing the essential building information in a digital format throughout the building lifecycle (Succar, 2009; Succar \& Kassem, 2015). The integration of heritage recording and BIM can document and manage historic buildings. This method takes into account historical data, and layers in plug-in libraries that represent historical components of the buildings, including both geometric and non-geometric attributes and relationships.

The first step in the HBIM process is the remote collection of survey data using terrestrial laser scanning with/or photogrammetry methods. Next, is designing a library of parametric architectural objects that could be used for the digital modelling of many historic buildings. Afterwards, these library objects are integrated with a technique for procedural modelling based on architectural rules and proportions automatically. Finally, the HBIM model is completed with a combination of the manual refinement of the automated model and manual placement of other required library objects (Fig. 6). Models are usually extracted by experts to reach the maximum level of detail of the geometric representation, which mostly represent existing real world models in the form of geospatial information systems (de Laat and van Berlo, 2011).

Once the HBIM model is generated, the next stage involves the integration of the 3D model into GIS for further management and analysis in order to have non-architectural information such as vector datasets, raster datasets, and attribute data (Fig. 7). A Geographic Information System (GIS) provides means for storing, visualising and analysing geographic data. Information, which is stored in database tables, is associated with geographic locations (map data) in order to spatially analyse data. Traditionally, GIS systems are compatible with 2D map data. However, latest developments allow for the development of 3D GIS systems, which have much better capabilities for management, analysis and visualisation of increasingly heterogeneous collections of data.

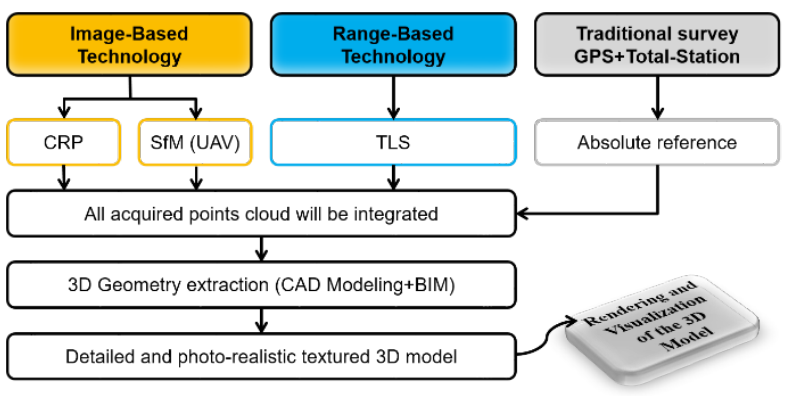

Figure 5. Integration of Range-Based, Image-Based Technologies and CAD Modelling extraction
Many applications and computer systems are designed for virtual reality that can be visited and navigated using maps. The integration between virtual reality technology and leading geographic information systems (GIS) will enhance the role of GIS as a unique information container and decrease the gap between geographic information with two dimensions and three dimensions, which represents a new generation of GIS.

\subsection{Development of a Holistic Application Based on AVR platforms}

Virtual Reality (VR) can be thought of as a precursor to Augmented Reality (AR). VR technologies can completely immerse a user in a synthetic environment and the users can be separated from the real world around them. By contrast, AR allows the users to see the real world in real time enhanced with virtual object information, once they are coordinated correctly in order to display a coherent superposition. In 1994, Paul Milgram presented the mix reality continuum (Milgram and Kishino, 1994). Merging the real and virtual worlds in a mixed reality system generates a new environment where physical and digital objects co-exist and interact. As presented in Figure 8, augmented reality (AR) and augmented virtuality (AV) are located between virtual environment (VE) and real environment (RE), while AV is closer to VE and AR is closer to RE.
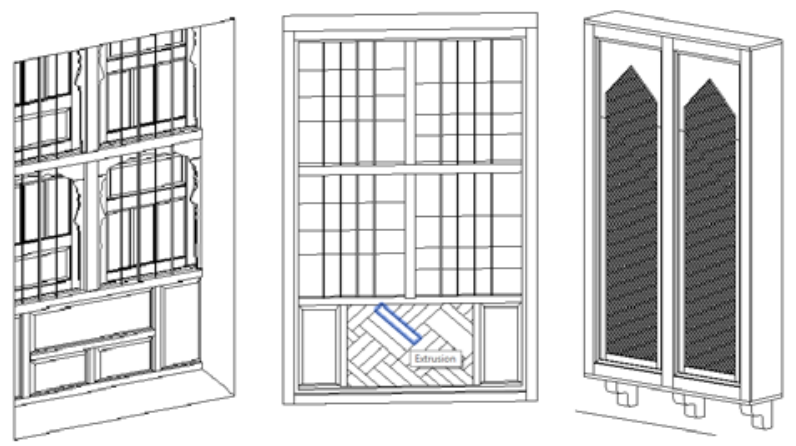

Figure 6. Generation of historical wooden windows elements

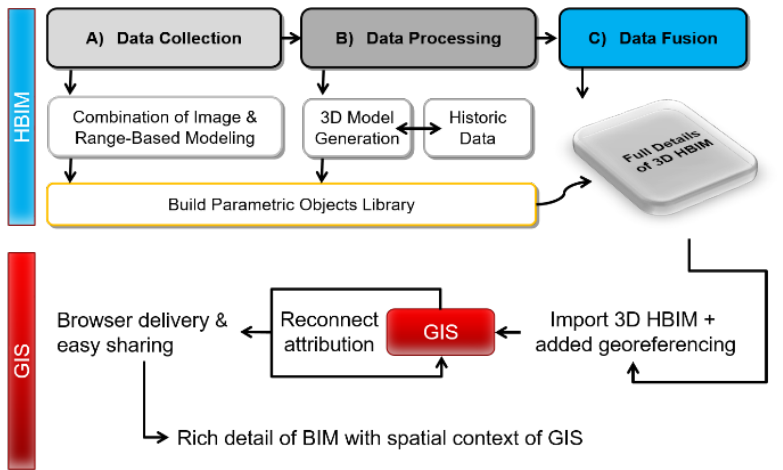

Figure 7. Integrating HBIM and GIS

There are many different ways to stimulate AR. One of the earliest and most well-known ways is:

1- Marker and image recognition: It recognizes the image or a particular feature on the image.

2- Geospatial augmented reality: It can recognize the location.

For Augmented Reality systems, smartphones have become a new and attractive platform (Billinghurst \& Henrysson, 2006). 
They help users connect with construction sites in order to observe them easily in the past, present, and future models. The concept for the AR application is the use of GPS that is already in the device to synchronize location data to BIM models. Therefore, the devices used such as tablets or smartphones would recognise the exact location using GPS coordinates and be able to overlay the corresponding site information from the BIM model on top of the real-world view. It gives the users the ability to see the 3D virtual view of the whole construction overlaid on the real-world view of the worksite easily.

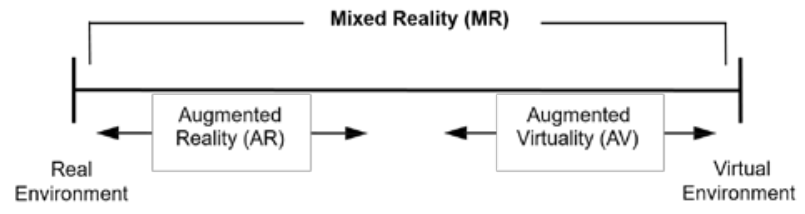

Figure 8. Milgram's reality-virtuality continuum

In the work of Keil et al. (2011), an iPhone-based App was developed as a history and architecture guide for tourism on a cultural heritage site: Darmstadt Artist's Colony, the Josef Maria Olbrich House, as the main example. The App provides textual background information on the architect and offers a 3D model view when run in 'classic information tour' mode (Fig. 9). However, when run in 'augmented reality tour' mode, the user can take a snapshot of the building ahead, and the App, after identifying the building, shows a 3D reconstruction of the building with information on the different elements of the building that have changed or are missing as an independent model viewed in the browser.

The 3D reconstruction reacts to user movements and changes its orientation and scale in response to the user's position using data from the phone's GPS and compass. It also responds to two-finger multi-touch pinch, zoom and rotating gestures. Although this App can provide the user with important information and a 3D model, the model used in this App has a sketch-like rendering, which curtails the 'Reality' aspect of AVR. Thus, the architectural elements of the model cannot be examined in detail.
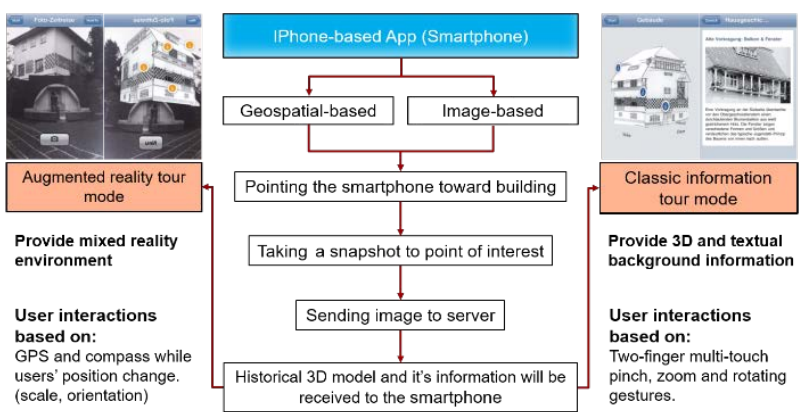

Figure 9. An App developed as a guide for tourism

Once the selected 3D model is generated, it is fed into AVR Platforms (Desktop PC, TV, wall mounted displays, 3D glasses or Head-mounted displays) to provide the user with an immersive experience. Historical Models with different levels of detail (LoD) are required for different purposes. For example, in the preservation model, a very high level of detail is necessary. Whereas in the model to be used for providing information to the tourists, relatively lower levels of detail are required to facilitate smooth visualization and interaction (typically on computationally limited hardware). High level of detail means large data volume, which may be difficult to render in the portable device that a tourist will be using. Primarily, there are two components of the proposed application. The VR component of the application enables the users to virtually walk past and inspect the models by using some interactive device. For the AR component, a anumber of enhancements are added to the previously generated 3D model including:

i. Interactive option to learn about the history and legacy associated with the building and location.

ii. Interactive option to learn about the architectural characteristics of the structures.

iii. Interactive option to digitally reconstruct the buildings and the locations as they were in during a certain historical period.

\section{EXPERIMENTAL RESULTS}

To provide the users with enhanced/augmented VR experience, the proposed methodology uses and integrates commercially available AVR interface devices, and collects data using different sensors present in those devices, based on the user's analysis requirements. Unity3D is used to convert a BIM model into a form that can explore a 3D model virtually, maintain the interactivity, and configure inside the real-time engine. One of the important advantages of Unity3D is referenced external files, such as scripts, textures and models. Furthermore, instead of being fully embedded, it can be dynamically reloaded after model changes. In addition, Unity can import geometry from FBX files when integrating 3D CAD or BIM files into a real-time environment, and can be deployed across a variety of platforms with little to no overhead. Thus, a 3D model can be exported as standalone applications onto handheld tablets running iOS or Android. Web applets for online use are supported as well, which help visitors interact remotely with the scene. Oculus Rift or HoloLens glasses are also considered for improved immersive visualization (Fig. 10).

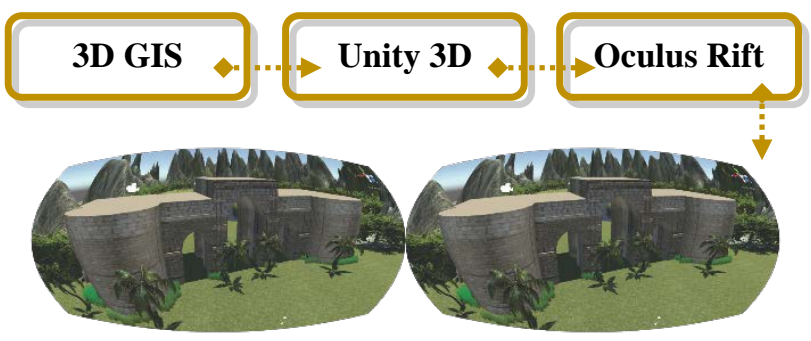

Figure 10. Immersive visualization environment using Unity 3D

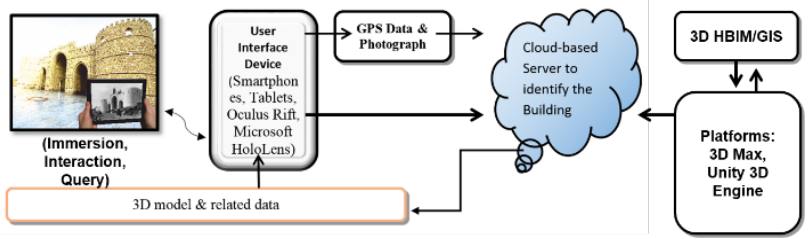

Figure 11. Schematic of the proposed framework for a real-time MR experience

The proposed framework includes an App that gathers data from the GPS receiver and the camera of the device. Once the location of the user is identified, it is possible to identify the historical building/monument/ landmark that the user is standing in front of. If there are multiple sites of interest at that 
location, the image from the device's camera can be used for pinpointing the exact site.

The data related to that particular site of interest is already present in a cloud-based-server, and can be streamed down feeding the user's device. The data can be 3D Models, Augmented 3D Models or interesting information regarding that particular site. Thus, the user can have a real-time AVR experience using this framework. A schematic of the proposed framework for AR is illustrated in Figure 11.

\section{CONCLUSIONS}

The proposed work aims to create a conceptual AVR model combined in a holistic pipeline that incorporates the needs and realities of tourism and heritage perservation within the context of the UNESCO world heritage site as a solution for digitally preserving and reconstructing the site, interacting with it, increasing contextual awareness and attracting global tourists. To achieve this outcome, it is necessary to carry out an extensive review of the existing approaches used to process and analyse LiDAR point clouds, model historic buildings and monuments, and preserve and restore such historic sites, as well as literature related to the combination of CRP, TLS and other technologies. A novel integrated approach involving HBIM, 3D GIS, with mixed reality (MR) and transformation between heterogeneous data is proposed. Therefore, using a combination of data sources collected by multiple technologies, a new integrated approach has been presented that increases context awareness of the architectural heritage of Jeddah city, improves users' spatial experience via portable devices, and provides users' interaction with the environment. Our focus is multidisciplinary research concerning both innovative Cultural Heritage Informatics and the use of technology for the digitization, representation, documentation, preservation, and communication of Cultural Heritage knowledge. This work serves as a reference source of the architectural heritage and of any changes, and contributes to the understanding of the architectural heritage of the historical elements using of MR as a novel visualization tool. It also contributes to the prediction of potential hazards and maintenance requirements of the historical monuments.

\section{ACKNOWLEDGEMENTS}

Special thanks to all staff members of the Geomatics Department in the Faculty of Environmental Designs at King Abdul Aziz University, for their support in this work by providing all instruments needed for this study. Also, the thanks continued to The Saudi Arabian Cultural Bureau in Canada, who facilitated the first author's Canadian studies.

\section{REFERENCES}

Al-Gabban, A. (2013). Historic Jeddah, The gate to Makkah [PDF file]. Saudi Commission for Tourism and Antiquities. Department of Antiquities and Museums.

Alitany, A. (2014). A new strategy of ICT integrated methodologies for 3D documentation: a case study of the projected wooden windows (The Roshans) in the historical city of Jeddah (Saudi Arabia).

Arnold, C., Huggett, J., Reilly, P., \& Springham, C. (1989). Mathrafal: A case study in the application of computer graphics. In Proceedings of the Conference on Computer Applications in
Archaeology (CAA), S. Rahtz and J. Richards, Eds. Vol. 16. 147-156.

Autodesk. (2011). “Revit”, www.Autodesk.com/revit (30 June 2017).

Baik, A., Yaagoubi, R., \& Boehm, J. (2015). Integration of Jeddah Historical BIM and 3D GIS for Documentation and Restoration of Historical Monument. ISPRS-International Archives of the Photogrammetry, Remote Sensing and Spatial Information Sciences, 1, 29-34.

Biek, L. (1985). Lernie XIV: Comparology and stereo video. In Proceedings of the Conference on Computer Applications in Archaeology (CAA). Vol. 12.1-35.

Billinghurst, M., \& Henrysson, A. (2006). Research Directions in Handheld AR. IJVR, 5(2), 51-58.

Böhler, W., \& Marbs, A. (2004). 3D scanning and photogrammetry for heritage recording: a comparison. In Proceedings of the 12th International Conference on Geoinformatics (pp. 291-298). Gavle University Press Sweden.

Buckland, P. Andwilcock, J. (1973). An experiment in the use of a computer for on-site recording of finds, and the use of remote terminals for archaeological site records. In Proceedings of Computer Applications in Archaeology 1, Science and Archaeology (CAA73). Vol. 9. George Street Press, Stafford, UK.

de Laat, R., \& Van Berlo, L. (2011). Integration of BIM and GIS: The development of the CityGML GeoBIM extension. In Advances in 3D geo-information sciences (pp. 211-225). Springer Berlin Heidelberg.

Dore, C., \& Murphy, M. (2012). Integration of HBIM and 3D GIS for Digital Heritage Modelling, Digital Documentation, 2223 October, 2012 Edinburgh, Scotland.

Grussenmeyer, P., Landes, T., Voegtle, T., Ringle, K., (2008). Comparison Methods of Terrestrial Laser Scanning, Photogrammetry and Tacheometry Data for Recording of Cultural Heritage Buildings.The International Archives of the Photogrammetry, Remote Sensing and Spatial Information Sciences, Vol. XXXVII.Part B5, pp. 213-218.

Höllerer, T.H., Feiner, S.K., (2004). Mobile augmented reality. In Karimi HA, Hammad A (eds) Telegeoinformatics: locationbased computing and services. CRC Press, pp. 392-421.

Höllerer, T.H., Feiner, S.K., (2004). Mobile augmented reality. In Karimi HA, Hammad A (eds) Telegeoinformatics: locationbased computing and services. CRC Press, pp. 392-421.

Kadobayashi, R., Kochi, N., Otani, H., Furukawa, R., (2004). Comparison and evaluation of laser scanning and photogrammetry and their combined use for digital recording of cultural heritage. International Archives of the Photogrammetry, Remote Sensing and Spatial Information Sciences, 35(5), pp. 401-406.

Keil, J., Zollner, M., Becker, M., Wientapper, F., Engelke, T., \& Wuest, H. (2011). The House of Olbrich-An Augmented Reality tour through architectural history. In Mixed and Augmented Reality-Arts, Media, and Humanities (ISMAR- 
AMH), 2011 IEEE International Symposium On (pp. 15-18). IEEE.

Koller, D. \& Levoy, M. (2006). Computer-Aided reconstruction and new matches in the forma urbisromae. Bull. Della CommissioneArcheol. Comunale di Roma.

Levoy, M., Pulli, K., Curless, B., Rusinkiewicz, S., Koller, D., Pereira, L., Ginzton, M., Anderson, S., Davis, J., Ginsberg, J., Shade, J., \& Fulk, D. (2000). The digital Michelangelo project. In Proceedings of ACM SIGGRAPH International Conference on Computer Graphics and Interactive Techniques.131-144.

Lindsay. Enhancing BIM with Augmented Reality. Retrieved from: http://www.augmentedev.com/blog/enhancing-bim-withaugmented-reality/ (30 June 2017).

Milgram, P., \& Kishino, F. (1994). A taxonomy of mixed reality visual displays. IEICE Transactions on Information and Systems, 77(12), 1321-1329.

Remondino, F., \& Campana, S. (2014). 3D Recording and Modelling in Archaeology and Cultural Heritage. BAR International Series, 2598.

Steuer, J. (1992). Defining Virtual Reality: Dimensions Determining Telepresence. Journal of Communication 42(4), pp 73-93.

Steuer, J. (1992). Defining Virtual Reality: Dimensions Determining Telepresence. Journal of Communication 42(4), pp 73-93.

Succar, B. (2009). Building information modelling framework: A research and delivery foundation for industry stakeholders. Automation in construction, 18(3), 357-375.

Unity (2017). Unity game Engine, from https://unity3d.com/ (30 June 2017). 